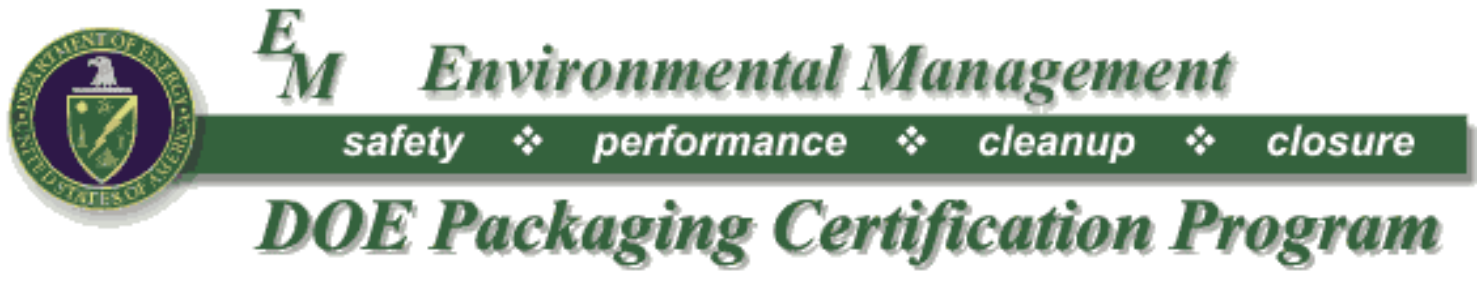

\title{
On The Application of Flow Forming to the Fabrication of \\ Type B Radioactive Material Package Containment Vessels, Rev. 1
}

This work was sponsored by the Department of Energy

Office of Packaging and Transportation (EM-45)

and performed by members of the

Packaging and Transportation Safety Group:

G. Mok, M. DeMicco, L. Fischer, L. Hagler,

E. Russell, J. Wen, R. Hafner, and B. Anderson

Global Security Principal Directorate

Lawrence Livermore National Laboratory

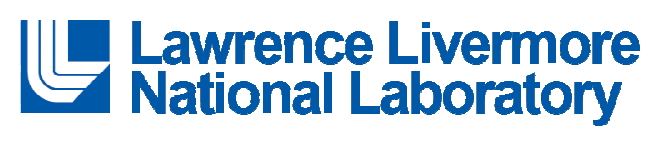

May 25, 2010

This work performed under the auspices of the U.S. Department of Energy by Lawrence Livermore National Laboratory under Contract DE-AC52-07NA27344. 


\section{Introduction}

Flow forming is a modernized and improved version of metal spinning, which is one of the oldest methods of chipless forming. The metal spinning method used a pivoted pointer to manually push a metal sheet mounted at one end of a spinning mandrel. This method was used to fabricate axisymmetric, thin-walled, light-weight domestic products such as saucepans and cooking pots. Although the method used a lathe-like machine, the repeatability of a finished product largely depends on the operator's skills. However, due to the inherent advantages and flexibilities of the metal spinning method such as simple tooling and light forming loads, and the modern trend towards near net shape manufacturing of thin-section light-weight parts, the method found new popularity in the aerospace industry during the 1950s. As a result, the modernized version of metal spinning, i.e., flow forming evolved. Instead of using a pivoted pointer, the flow forming method uses rollers with automated controlled movements. The rollers force specimen material to flow in the axial and radial directions of the mandrel. Thus, flow forming has significantly improved flexibility and accuracy in forming parts with large thickness variation.

Since 1950, flow forming has been used to produce rocket nose cones, rocket motor cases, gas turbine components, and dish antennas in the aerospace industry. It has also produced power train components and wheels in the automobile industry, and gas bottles and containers for storage applications. The recent proposal in the radioactive material (RAM) packaging community to use flow forming for mass production of small containment vessels for drum packages is a natural continuation of the trend. With more than fifty years of proven successful application, flow forming can most certainly produce the containment vessel. The only concern is whether the finished vessels would have the required quality and stability for the RAM containment application.

We will discuss how the vessel can have the special material properties and stabilities required for a RAM containment vessel. The first section presents details of the flow forming process. The next section addresses the probable causes and consequences of flow forming effects on metal properties. The third section discusses how the American Society of Mechanical Engineers (ASME) Boiler and Pressure Vessel (B\&PV) Code, Section III (the Code currently for controlling the design and fabrication of RAM containment vessels) addresses the possible effects of flow forming on material properties. Finally, based on this information and on the engineering experience with RAM packages, we propose a list of requirements to assure adequate quality of flow formed RAM containment vessels. 


\section{The Flow Forming Process}

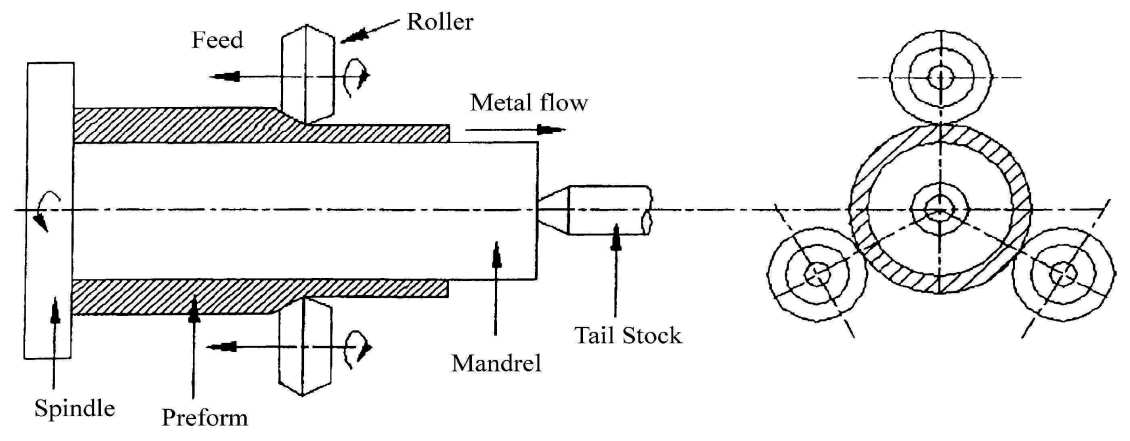

Fig. 1: The (backward) flow forming setup and operation

The above schematic depicts a typical (backward or reversed) flow forming process. The raw material to be processed is called a preform. The shape, the amount of material, and the material properties must be designed by the flow former to achieve a quality product. The preform is made by machining, forging, or deep drawing. To start the flow forming process, the preform is spun and compressed against a rotating mandrel and a set of rollers to give the flow formed part the desired shape. The gap between the mandrel and the rollers determines the thickness of the finished product. The gap can be programmed to change along the length of the product. To minimize the cold-work stresses and resulting micro-cracks, the operation may need to be completed in multiple passes and possibly with intervening stress-relieving heat treatments of the preform.

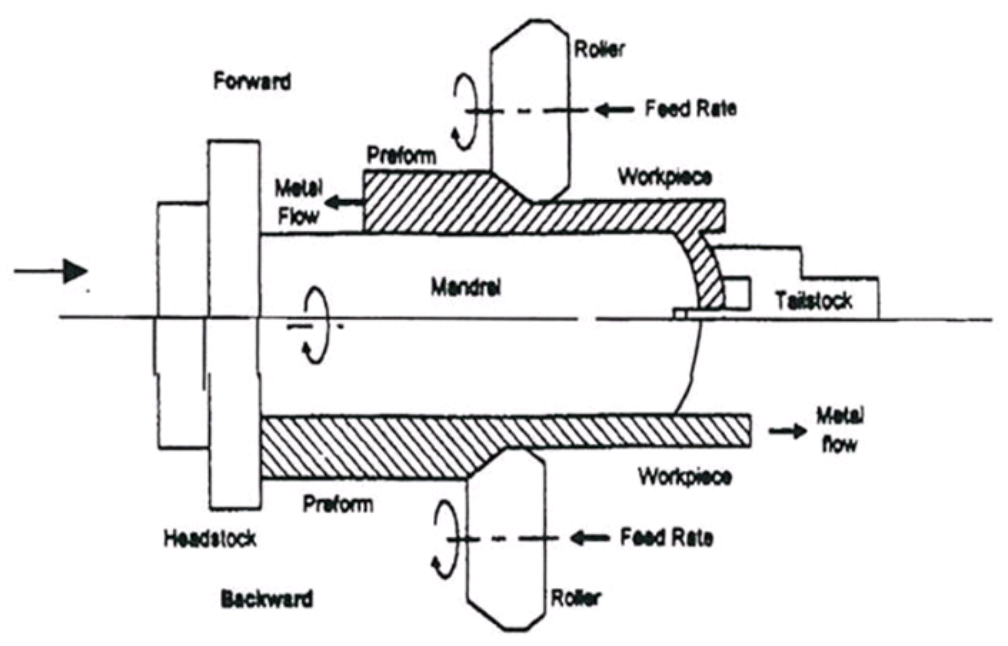

Figure 2 : Forward and backward flow forming 
Figure 2 above illustrates two alternative flow forming operations: the forward and the backward operations. The forward operation is used for forming a container or tube with one partially or fully closed end. The backward operation is for forming a tube with both ends fully open. In the forward operation, the preform metal flow and the rollers move in the same axial direction of the mandrel; whereas, in the backward operation, the metal and the roller move in opposite directions. Accordingly, the forward operation is similar to drawing, while the backward operation is like extrusion. During the operation, the metal directly under the rollers is always in compression. The stress in the forwardformed specimen segment is tensile, while there is no stress in the backward-formed specimen segment. As a result, the two operations do not have the same problems. The following defects of the backward flow forming have been observed: surface roughness, microcracks, macrocracks, diametral growth, ovality, and premature bursting. The purity, uniformity, and grain size of the material, the feed speed, the gap size between the mandrel and the perform, and the depth of cut are factors affecting the defects.

According to PMF (Precision Metal Forming) Industries, Inc., a "flow-former" in Pennsylvania, flow forming is ideal for:

- Axisymmetrical thin-walled products with controlled variable wall thickness and final product thickness between 0.020 and 0.2 inches, diameter between 1 and 24 inches, and length-todiameter ratios greater than 3.5 to 1

- Products made of difficult-to-form materials, including stainless steel, Hastelloy, Inconel, and other heat-resistant materials

- Products requiring various additional manufacturing processes, including machining, welding, and finishing

- Products that can benefit from the effects of cold working, such as increased strength, surface hardness, and wear resistance

- Products requiring tolerances exceeding the capabilities of deep drawing or spinning, and precision approaching that of machined parts

The containment vessel of small RAM transportation packages seems to be an ideal product for flow forming. 


\section{Flow Forming Effects}

Flow forming is a cold work (energy) process, in which a powerful force is applied to a material to permanently deform it without heating. Only a small percentage of the cold work done by the applied force is converted to heat--the rest of the work/energy is used to permanently deform the microstructure of the material. The microstructure of a metal is comprised of randomly distributed and oriented crystal lattices, or grains, that are separated by grain boundaries. When a metal solidifies, tiny metal crystals with a lattice structure emerge from many randomly distributed nucleation sites. (Metal atoms naturally arrange themselves into a lattice crystalline structure with repeated identical unit cells as building blocks.) The crystal lattices expand by involving more metal atoms until they meet and establish grain boundaries. An undeformed metal after solidification or recrystallization has crystal grains with insignificant internal stresses and few line defects (dislocations) within the lattice structure. To deform the metal permanently in cold work, the applied force will have to:

- Damage individual crystal grains by moving existing dislocations and generating many more new ones within the lattice crystal structure

- Crush the microstructure and leave a significant residual stress/strain field in the deformed microstructure

- Induce phase changes and precipitations of some material constituents in the grain boundaries

Changes to the metal's microstructure depend on the extent of the cold work, the degree and duration of the service temperature, and the alloy composition. All of these changes to the microstructure can be either unstable themselves or cause unpredictable long-term behaviors. As a result, changes in the microstructure result in property changes of the deformed metal including:

- Increase in the strength (the yield strength and tensile strength) and hardness

- Decrease in the ductility (elongation, reduction of area) and impact toughness

- Decrease in resistance to pitting corrosion and other long-term environmental attacks

- Increase in cracking susceptability in the heat affected zone (HAZ) of welds

There are other cold work effects, such as those on fatigue life and strength, creep rate and rupture strength, stress corrosion cracking, and sigma phase embrittlement of stainless steels. Some of these effects have been investigated and properly considered in codes and standards, while some are still not well understood. The common interest is in the increase of strength and hardness, because the effects render cold working an effective way to harden a metal-- especially for metals like 304 stainless steel, which cannot be hardened by heat treatment. Designers are usually willing to exchange less ductility for greater strength. However, for the containment vessel for RAM, this trade off may not be a prudent practice. Regulatory Guides 7.11 and 7.12 have shown that impact toughness is essential for packaging design, and the rules for packaging are more restrictive than the rules for pressure vessels. 
The primary cold-work effects on the material strength are not really reversible due to the permanent deformation of an interlocking three-dimensional (3D) microstructure. However, the effects can be practically removed by a process called annealing. In general, annealing refers to three processes: recovery, recrystallization, and grain growth. The recovery process, which occurs immediately following the cold work, is the result of elastic recovery and stress relaxation. The process can significantly reduce the residual stresses and the associated risk of developing hair cracks around impurities and inclusions. The benefits of recovery can be enhanced by raising the temperature, but the process can never produce appreciable changes in the microstructure. Significant changes only come from the recrystallization process. In recrysatllization, tiny new crystal grains start to appear and expand in areas with significant cold work, and these new grains eventually “absorb' all the deformed old crystal grains. At the end, the new damage and stress-free grains replace all of the old damaged and stressed grains. Accompanying this grain replacement, the metal properties prior to the cold work, such as decreased strength and higher ductility would return. Thus the cold work effects appear reversed.

The initiation and the rate of progress (the kinetics) of recrystallization depend on the extent of cold work, the metal temperature, the passing of time, and the alloy composition. For a given amount of cold work, the recrystallization can occur in a short period of time (in minutes and hours) at a high temperature. It can also occur in an extended period of time (days and months) at a lower temperature. The recrystallization temperature published in handbooks refers to the temperature in which the recrystallization can complete in one hour. For cold-forming strain less than 20 percent, recrystallization is generally considered unlikely in the service life of an austenitic stainless steel component at a service temperature sufficiently below the creep temperature of $1050^{\circ} \mathrm{F}$. The creep temperature is the temperature below which the material shows insignificant creep behavior. However, recrystallization can occur when the service temperature exceeds the creep temperature even occasionally. Thus, the desirable cold-work effects, including the increase in strength and hardness can become unreliable and therefore undesirable. This is probably the reason why ASME Code Subsection NB chooses to ignore the increase in strength due to cold work. It is also the reason for ASME code Subsection NH to require removal of all cold work effects by complete recrystallization. The following section of this report presents the requirement details of both ASME code subsections.

Following the recrystallization process is the grain growth stage of the annealing process. For a component subjected to various extents of cold work at different parts of the component, the final grain size (after annealing) may not be very uniform. For properties that are sensitive to grain size, including creep properties, one may need to keep the grain size variation within an acceptable range according to material specifications.

Some of the cold-work effects can only be removed by solution heat treatment or solution annealing. In the this process, the metal is heated to a suitably high annealing temperature and kept at the temperature for a sufficiently long time to allow the harmful precipitations in the grain boundaries to dissolve and their constituents to return through diffusion to their prior-to-cold-work positions in the metallic solid solution. The constituents will be locked in the solid solution if the metal is cooled rapidly (quenched). The solution annealing temperature, the holding time, and the cooling rate depend on the precipitation and the solid solution. An annealing temperature of $1900^{\circ} \mathrm{F}$ or greater, a holding time of 
more than 30 minutes, and a rapid quenching in water are used to separate and dissolve the metallic compound chromium carbide from the grain boundaries of austenitic stainless steels. The chromium carbide causes chromium depletion in grain boundaries and leads to intergranular corrosion of the stainless steels.

The following two figures provide a graphical overview of the relationship among microstructure, coldwork effect, and annealing:

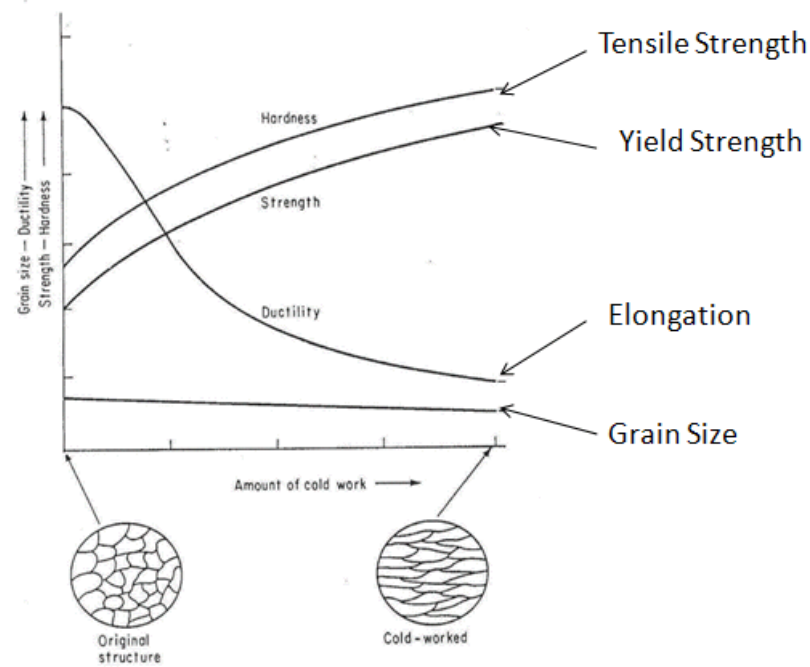

Figure 3 : Cold work effect on microstructure and mechanical properties

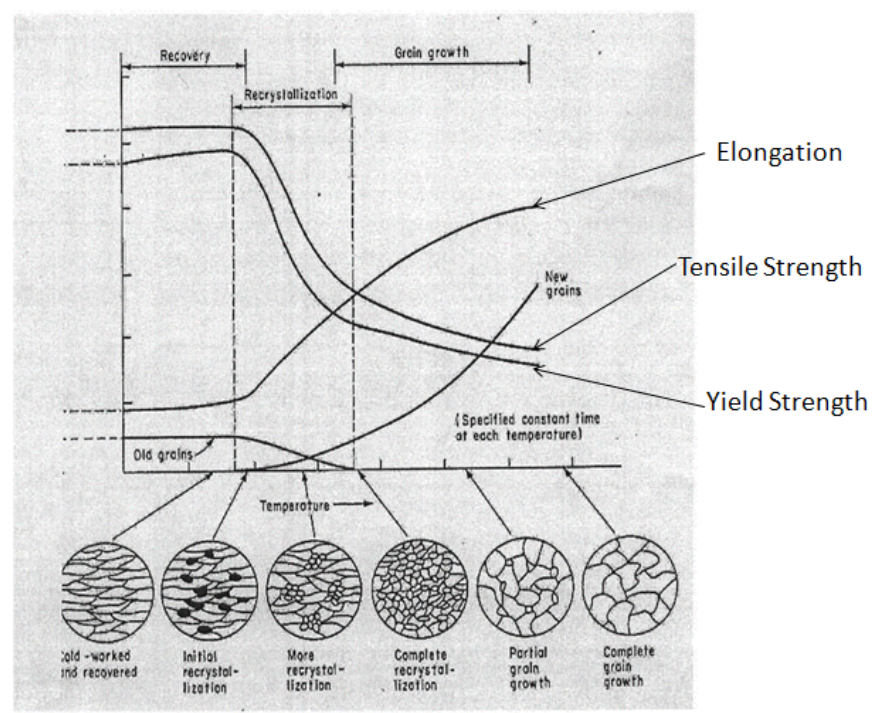

Figure 4 : Annealing effects on microstructure and mechanical properties 


\section{Codes and Standards}

We did not locate any established codes and standards for the application of flow forming. The ASME B\&PV codes and ASTM standards, part of which we are using for packaging engineering, do not address flow forming specifically.

The ASME Code Section III, Subsection NB, which we are using for the design and construction of the containment vessel of Category I packages (with the highest risk), contains rules for cold forming and bending, which we assume to include flow forming:

Article NB-4212 states that any process can be used for hot or cold form or bend pressure-retaining material, provided the required dimensions are attained, and provided the impact properties of the material (when required) are not reduced to below the minimum specified values, or they are effectively restored by heat treatment following the forming operation. Article NB-4212 continues that (when required) the process shall be qualified for impact properties as outlined in NB-4213.

Article NB-4213 states that applicable tests shall be conducted to determine that the required impact properties of NB-2300 are met after straining (or forming).

NB-2300 requires that all pressure-retaining material shall be impact tested except (a) material with a nominal section thickness of 5/8 inches and smaller; (b) bolting with a nominal size of 1 inch; (c) bars with a nominal cross-sectional area of 1 in. $^{2}$; (d) austenitic stainless steel; and (e) nonferrous material.

The thickness and material of all containment vessels to be made by flow forming in the future are very likely to fall within the range of impact-test exemption. Thus, heat treatment after flow forming is most likely not required by ASME Section III, subsection NB. This expectation is consistent with Article NB4652 that identifies situations exempted from heat treatment after cold bending and forming, unless the design specifications require it.

Although the ASME code allows pressure-vessel components made by cold forming to be used in the asbent/formed condition, the code does not allow the designer to take advantage of the increased strength of the cold-formed material. The allowable stress published in Section II Part D of the code is based on the fully annealed material. An example of this is the allowable stress for the $304 \mathrm{~L}$ stainless steel specified by ASME Material Specification SA-666. Although SA-666 provides strength information for annealed and several cold-work conditions, the allowable stress published in Section II Part D for material of Specification SA-666 is based entirely on the annealed condition.

In conclusion, we believe the requirements of ASME Section III, Subsection NB imply the following:

- The requirement of heat treatment (annealing) after cold forming is optional. It is the owner's or design engineer's choice. The frequent usage of the phrases, "when required" and "if the design specifications require" used to describe the heat treatment requirement makes this intention of the Code obvious. 
- The Code assumes all cold work to be limited (less than 20 percent), so that no post-coldforming NDE of the finished product is required, and the material properties following the cold work will be stable (unchanged) at low temperatures where the code is applicable

- In addition, the code expects the reduction of material ductility and resistance to corrosion and intergranular attack to be inconsequential. Therefore, no special tests warning about the possible consequence of low ductility and low resistance to intergranular attack are prescribed

To demonstrate the importance of removing cold work effects for higher temperature applications, the code requirements of ASME code Section III, Subsection NH for cold forming are evaluated here. Subsections NH and NB are used for design and fabrication of the Class 1 (most safety related) reactor components. NB is for application in light water reactors where service temperature is kept below the stainless steel creep temperature (about $1050^{\circ} \mathrm{F}$ ) while $\mathrm{NH}$ is for application in breeder reactors where the service temperature often exceeds the creep temperature. $\mathrm{NH}$ was written as a supplement to NB; it presents only changes and additions to the requirement of NB. Article NH-4212 clearly identifies the following major changes from NB to $\mathrm{NH}$ :

- Post fabrication (cold forming) heat treatment is optional only if the maximum fabricationinduced local strains do not exceed 5 percent or if written justification is provided in the design report. The justification should include consideration of property variability through the material section.

- The justification option is not permitted for certain materials if the component has excessive cumulative high-temperature exposures. The option is also not permitted for any austenitic stainless steel that is subjected to greater than 20 percent strain

- For all austenitic material (except Alloy $800 \mathrm{H}$ ), the required post fabrication heat treatment shall consist of the heat treatment described in the material specification.

The mandatory requirement for post fabrication heat treatment is probably due to the discovery of two unstable or unpredictable cold-work effects on creep properties: (1) recrystallization to a finer grain size leads to an increase in creep rate and a decrease in rupture strength, and (2) a decrease in ductility renders the component vulnerable to premature failure from the formation of cracks. However, due to the lack of complete understanding of the relationship between the cold work effects and the observed failures, the imposition of post fabrication heat treatment may not solve all the problems. 


\section{Recommendations}

All foregoing information indicates that flow forming is an adequate and efficient method for mass production of small RAM containment vessels. The only concern is in the quality assurance and control of the process. This concern is the result of the following:

- There is a limited amount of experience with this application

- Flow forming causes more-than-usual extensive cold work

- With increasing extent of cold work, the effects on metal properties may become more unstable and unpredictable

- Ignoring the cold work effects in analysis, as suggested in ASME Code Subsection NB, would lead to inconsistency and confusion between analysis and test results

To minimize the quality assurance concern, we recommend a thorough qualification of the flow forming equipment, operation, and operators prior to establishing the production quality assurance requirements and procedures. The following are the key elements of the thorough qualification process:

- The package design engineer must work closely with the flow former on the selection of material, design and fabrication of the preform, and on the planning, tooling, and qualification of the flow forming operation

- The material of the preform shall meet the desired flow forming and RAM containment vessel requirements, and shall be selected jointly by the flow former and the package engineer from ASME approved specifications (ASME Code Section II Parts A, B, and D)

- The forming operation must not produce unacceptable defects. The sensitivity of the defects to all operation parameters must be identified, and the permissible range of operational parameters must be established

- The finished vessel shall receive a solution annealing heat treatment, which shall be determined by a qualified metallurgist if it is not specified in the preform-material specification

- The finished vessel shall be inspected before and after the annealing heat treatment for precision in geometries and dimensions

- After the heat treatment, the finished vessel shall receive a full (100 percent) surface and volumetric NDE. The NDE methods and acceptance criteria must follow appropriate ASME Subsection NB Article NB-2000 rules for NDE class 1 pressure retaining materials and Article NB4000 for NDE Class 1 finished pressure vessels and components

- After the heat treatment, the finished vessel shall be hydrostatic-pressure tested at 150 percent maximum normal operating pressure (MNOP) as required by $10 \mathrm{CFR71}$ and following the procedure described in ASME Code Subsection NB Article NB-6000 for the same test 
- Before and after the heat treatment, samples of finished-vessel material shall be tested according to ASTM Standards E8/E8M for mechanical properties. The minimum results after the heat treatment must be within 5 percent of the corresponding property values in the material specification

- If impact testing is required by the material specification or the ASME code Subsection NB, samples of finished-vessel material shall be impact tested according to ASTM Standard E23. Reduced-size specimens may be used, if necessary and permitted by the ASTM Standards. The results must be equal to or greater than the acceptable value specified by the packaging engineer and consistant with Regulatory Guidance 7.11 and 7.12 requirements

- If required by the material specification, samples of finished-vessel material from various vessel locations shall be measured after the heat treatment for average grain size using the method described in ASTM Standard E112. The results should be within the material-specification defined range

- Before and after the heat treatment, samples of finished-vessel material shall be tested according to ASTM Standard A262 for susceptibility to intergranular attack, if the vessel material is austenitic stainless steel

- No repair shall be allowed for defective or damaged vessels

- If the vessel is made of flow formed parts by welding and/or machining, the flow formed parts must be fully solution annealed, and NDE must be performed according to ASME Rules NB-2000 and NB-4000 prior to welding and machining, and the completed vessel must meet all appropriate ASME NDE requirements in Article NB-4000 


\section{References}

- $\quad$ ASME Boiler and Pressure Vessel Code (2007a), Section II, Part A, Ferrous Material Specifications, The American Society of Mechanical Engineers, New York

- $\quad$ ASME Boiler and Pressure Vessel Code (2007b), Section II, Part B, Non-ferrous Material Specifications, The American Society of Mechanical Engineers, New York

- $\quad$ ASME Boiler and Pressure Vessel Code (2007c), Section II, Part D, Properties (Customary) Materials, The American Society of Mechanical Engineers, New York

- ASME Boiler and Pressure Vessel Code (2007d), Section II, Part D, Non-mandatory Appendix A, Metallurgical Phenomena, The American Society of Mechanical Engineers, New York

- $\quad$ ASME Boiler and Pressure Vessel Code (2007e), Section III, Division 1--Subsection NB, Class 1 Components, Rules for Construction of Nuclear Facility components, The American Society of Mechanical Engineers, New York

- ASME Boiler and Pressure Vessel Code (2007f), Section III, Division 1--Subsection NH, Class 1 Components in Elevated Temperature Service, Rules for Construction of Nuclear Facility components, The American Society of Mechanical Engineers, New York

- ASME Boiler and Pressure Vessel Code (2007g), Section II, Part A, Ferrous Material Specifications, SA-466, Specification for Annealed or Cold-worked Austenitic Stainless Steel sheet, Strip, Plate, and Flat Bar, The American Society of Mechanical Engineers, New York

- Cieslak, M. J.; (1993), Cracking Phenomena Associated with Welding, ASM Handbook, v. 6, Welding, Brazing, and Soldering, pp. 87-96, ASM International

- Davidson, M. J.; Balasubramanian, K; Tagore, G. R. N.; (2008a), An Experimental Study on the Quality of Flow-formed AA6061 Tubes, Journal of Material Processing Technology, v. 203

- Davidson, M. J.; Balasubramanian, K; Tagore, G. R. N.; (2008b), Experimental Investigation on Flow-forming of AA6061 Alloy-A Taguchi Approach, Journal of Material Processing Technology, v. 200

- Degarmo, E. P.; Black, J. T.; Kosher, R. A.; (2003), Materials and Processes in Manufacturing $\left(9^{\text {th }}\right.$ ed.), Wiley

- Elgun, S. Z.; (2002), MET205--Material Science Course Notes, Farmingdale State College, Farmingdale, New York

- Elhoud, A.; Ezuber, H.; and Deans, W.; (2010), Influence of Cold Work and Sigma Phase on the Pitting Corrosion Behavior of 23 Chromium Super Duplex Stainless Steel in 3.5\% Sodium Chloride Solutiuon, Materials and Corrosion, v. 61(3) 
- Flewitt, P. E. J.; and Wild, R. K.; (2001), Grain Boundaries - Their Microstructure and Chemistry, John Wiley, Chichester, England

- Fonte, M; (2010), Private communications

- Fonte, V.; Tosdale, J.; and Chang, C-W.; (1999), Flow forming of Zirconium and Titanium Pipe, http://www.wahchanglabs/pdf/1999/1999022.pdf

- Gurry, R. W.; Jacob, E. M; and Allen, S. H.; (1971), Welded Austenitic Stainless Steel Tubing, Effect of Cold Work and Annealing on corrosion Resistance, Ind. Eng. Chem Prod. Res. Dev., v. 10(1)

- Gutman, E. M.; Solovioff, G.; and Eliezer, D; (1996), The Mechanochemical Behavior of Type 316L Stainless Steel, Corrosion Science, v. 38(7)

- Homma K,; Miki, C.; and Yano H.; (1998), Fracture Toughness of Cold Worked and Simulated Heat Affected Structural Steel, Engineering Fracture Mechanics, v. 59(1)

- Hornbach, D.; and Prevey, P. S.; (2001) The effect of Prior Cold Work on Tensile Residual Stress Development in Nuclear Weldments, Proceedings, 2001 ASME Pressure Vessels and Piping Conference, July 22-26, Atlanta, Georgia

- Humphreys, F. J. and Hatherly, M., (2004), Recrystallization and Related Annealing Phenonmena, $2^{\text {nd }}$ Ed., Elsevier, Oxford, U.K.

- Morris, J. W. Jr.; (2001), The Influence of Grain Size on the Mechanical Properties of Steel, Proceedings, International Symposium on Ultra fine Grained Steels, S. Takaki and T. Maki, eds., Iron and Steel Inst. Japan, Tokyo

- Peguet, L.; Malki, B.; and Baroux, B.; (2007), Influence of Cold Working on the Pitting Corrosion resistance of Stainless Steels, Corrosion Science, v.49

- PMF Industries, Inc., (2010a) Going with the Flow: Cost Containment with Flow Formed Parts, http://www.flowformingplus.com

- PMF Industries, Inc., (2010b) Going with the Flow: Understanding Flow Forming, A Precision Metal Forming Process Uniquely Capable to Accomplish your Design Objectives, http://www.flowformingplus.com

- PMF Industries, Inc., (2010c) http://www.flowformingplus.com

- Rajan, K. M.; and Narashimhan, K.; (2001), An Investigation of the Development of Defects During Flow Forming of High Strength Thin Wall Steel Tubes, Practical Failure Analysis, v. 1(5), October 
- Rajan, K. M.; and Narashimhan, K; (2003), Failure Studies on Flow Formed High Strength Pressure Vessl: A Case Study, Jpournal of Pressure Vessel Technology, August

- Rajan, K. M.; and Narashimhan, K.; (2002c), An Approach to Selection of Material and Manufacturing Processes for Rocket Motor Cases Using Weighted Performance Index, Journal of Materials Engineering and Performance, v. 11(4), January

- Rajan, K. M.; Deshpande, P. U.; and Narashimhan, K; (2002a), Effect of Heat Treatment of Preform on the Mechanical Properties of Flow Formed AISI 4130 Steel Tubes --- A Theoretical and Experimental Assessment, Journal of Materials Processing Technology 125-126, January

- Rajan, K. M.; Deshpande, P. U.; and Narashimhan, K.; (2002b), Experimental Studies on Bursting Pressure of Thin-Walled Flow Formed Pressure Vessels, Journal of Materials Processing Technology pp. j125-126, January

- Wong, C. C.; Dean, T. A.; and Lin, J.; (2003), A Review of Spinning Shear Forming and Flow Forming Processes, International Journal of Machine Tools \& Manufacture, v. 43, pp. 1419-1435 